\title{
Laclau y la dialéctica. Notas sobre un desencuentro con Hegel (y con Marx)
}

\author{
Laclau and the dialectic. Notes on a failed meeting with Hegel (and with Marx)
}

\author{
Martín Retamozo *
}

\begin{abstract}
Resumen: La teoría política de Ernesto Laclau ha generado un sin número de debates en el campo académico de izquierda. El calificativo de Post-marxismo para referir a su teoría originó controversias sobre su ruptura con Marx y la presencia de la herencia marxista en su obra. En este sentido, una de las propuestas del posmarxismo es abandonar la dialéctica por su carácter determinista. Para Laclau es la dialéctica hegeliana la culpable de introducir la lógica de la necesidad en el marxismo y esto le impide pensar la contingencia. Este artículo estudia la lectura que hace Laclau de la dialéctica hegeliana en diferentes obras y revisa su trabajo sobre las nociones de determinación, negatividad y contingencia. Una revisión de estos conceptos puede restituir un concepto de dialéctica no-determinista y acorde al pensamiento político posfundacional para pensar la ontología social y los antagonismos.
\end{abstract}

Palabras Clave: Laclau, Hegel, Marx, Post-marxismo, dialéctica, hegemonía

Abstract: The political theory of Ernesto Laclau has generated several debates in the academic left. The label of Post-Marxism to his theory originated discussions about his relationship with Marx and the presence of the Marxist legacy in his work. In this matter one of the proposals of post-Marxism is abandoning dialectics. For Laclau, the Hegelian dialectic is guilty of introducing the logic of necessity in Marxism. This impedes analysis of contingency in history. This article studies Laclau's reading of Hegelian dialectic in different works and analyzes his writings on the notions of determination, negativity and contingency. A review of these concepts can restore an adequate concept of dialectic non-deterministic for the postfundational political thought.

Key words: Laclau, Hegel, Marx, Post-marxism, dialectic, hegemony

Recibido: 20/04/2017

Aceptado: 02/06/2017

* IdIHCS- UNLP/CONICET. Investigador del CONICET. Doctor en Ciencias Sociales (FLACSO-México). Profesor de Filosofía y Magister en Ciencias Sociales. (Universidad Nacional de La Plata- UNLP, Argentina). Profesor del Doctorado en Ciencias Sociales y en la Licenciatura en Sociología (UNLP), $\triangle$ martin.retamozo@gmail.com 


\section{Introducción}

"Entonces, olvidemos a Hegel"

(Ernesto Laclau, 2005:186)

Ernesto Laclau es una de las persistentes presencias en el campo de la teoría política de izquierda en las últimas cuatro décadas. Desde sus primeros trabajos, sus ideas han provocado una serie de debates particularmente intensos que articularon disquisiciones teóricas, querellas hermenéuticas sobre diferentes autores y refinamiento categorial con apasionadas discusiones políticas sobre los procesos contemporáneos y los proyectos de izquierda, socialistas, emancipatorios o de liberación. Hacia finales de los años setentas sus intervenciones ${ }^{1}$ suscitaron controversias, especialmente, por los intentos de conciliar un tipo de populismo con el socialismo, en un contexto teórico marcado por el althusserianismo y uno histórico signado por la presencia de movimientos de liberación nacional en países del Tercer Mundo ${ }^{2}$. Estas polémicas cobraron nuevos bríos cuando en los años ochenta, en un contexto de crisis de la izquierda y cambios en procesos políticos en Europa y en América Latina, publicó -quizás- su obra más influyente (junto a Chantal Mouffe) Hegemonía y Estrategia socialista. Hacia una radicalización de la democracia (de ahora en adelante, HyES) (1985) ${ }^{3}$. Una nueva lectura de Gramsci en el terreno marcado por el posestructuralismo (psicoanalítico y lingüístico), un espacio para los nuevos movimientos sociales y la propuesta de una democracia radical, alimentaron intensas polémicas. ${ }^{4}$ El provocador rótulo de "Post-marxismo"s obnubiló a muchas de las recepciones que reaccionaron más centradas en denunciar una renuncia al marxismo al calificar la posición de Laclau y Mouffe de ex-marxismo ${ }^{6}$ o pre-marxismo ${ }^{7}$ y una concesión al posmodernismo ${ }^{8}$, cuando no al neoliberalismo. Más allá de las recepciones autoadjudicadas como genuinamente marxistas, es innegable que a lo largo de la obra de Laclau, uno de los debates más intensos transita el terreno espinoso de su relación con Marx o, en otros términos, la relación entre marxismo y postmarxismo. ¿Cuáles son las rupturas que hace Laclau respecto de Marx y cuáles las

\footnotetext{
${ }^{1}$ Laclau, Ernesto. Politics and ideology in Marxist theory: Capitalism, fascism, populism. New Left Books, 1977.

2 Al respecto: Mouzelis, Nicos. "Ideology and class politics: a critique of Ernesto Laclau." New Left Review 112 (1978): 45. Mucho más sutiles han sido las recepciones de De Ipola y Portantiero: Portantiero, Juan Carlos, and Emilio De Ipola. "Lo nacional popular y los populismos realmente existentes." Nueva Sociedad 4 (1981): 7-18.; De Ipola, Emilio. "Populismo e ideología (A propósito de Ernesto Laclau:" Política e ideología en la teoría marxista")." Revista Mexicana de Sociología 41.3 (1979): 925-960, y De Ípola, Emilio de Ipola (198a): Ideología y discurso populista, México, Folio Ediciones

${ }^{3}$ Laclau, Ernesto, and Chantal Mouffe. Hegemony and socialist strategy: Towards a radical democratic politics. LondonVerso, 1985.

${ }^{4}$ Como Laclau lo reconoce, la idea de "democracia radical" es fundamentalmente sostenida por Chantal Mouffe (Laclau, Ernesto, Nuevas reflexiones sobre la revolución de nuestro tiempo. Nueva Visión, 2000.). Al respecto puede consultarse Wenman, Mark Anthony. "Laclau or Mouffe? Splitting the difference." Philosophy \& social criticism 29.5 (2003): 581-606.

${ }^{5}$ Para un itinerario del postmarxismo ver Sim, Stuart. Post-Marxism: an intellectual history. Routledge, 2013.

${ }^{6}$ Geras, Norman. "Ex-Marxism without substance: Being a real reply to Laclau and Mouffe." New Left Review 169 (1988): 34.

7 Boron, Atilio A. "¿" Postmarxismo"? Crisis, recomposición o liquidación del marxismo en la obra de Ernesto Laclau." Revista mexicana de sociología (1996): 17-42.

${ }^{8}$ Boucher, Geoff. (2000), " Hegel and Postmodern Discourse Theory,” 1-3. Paper presented at the Hegel-Marx-Derrida Seminar, Melbourne 18th February 2000. (disponible en https://www.marxists.org/reference/archive/hegel/txt/gb2000 2.htm)
} 
continuidades? ¿Qué es lo pos respecto al marxismo? Y ¿qué queda del marxismo si lleva el prefijo pos? En la Introducción a HyES, nuestros autores lanzan las piedras:

En este punto es necesario decirlo sin ambages: hoy nos encontramos ubicados en un terreno claramente posmarxista. Ni la concepción de la subjetividad y de las clases que el marxismo elaborara, ni su visión del curso histórico del desarrollo capitalista, ni, desde luego, la concepción del comunismo como sociedad transparente de la que habrían desaparecido los antagonismos, pueden seguirse manteniendo hoy. Pero si nuestro proyecto intelectual en este libro es posmarxista, está claro que él es también posmarxista. Es prolongando ciertas intuiciones y formas discursivas constituidas en el interior del marxismo, inhibiendo y obliterando otras, como hemos llegado a construir un concepto de hegemonía que, pensamos, puede llegar a ser un instrumento útil en la lucha por una democracia radicalizada, libertaria y plural ${ }^{9}$.

Este párrafo es sintomático porque muestra como las críticas al marxismo operan en distintos planos. La primera presenta un desacuerdo teórico por una limitación paradigmática para pensar la configuración de los sujetos sociales (la cuestión de la subjetividad y las clases sociales como agentes ${ }^{10}$ ). La segunda señala un desacuerdo con una afirmación empírica relacionada al curso de la historia y el desarrollo del capitalismo hacia una simplificación polarizada de lo social. La tercera se enfoca en el proyecto político (el comunismo como reconciliación) ${ }^{11}$.

En este artículo nos interesa particularmente la crítica teórica que se ubica en el plano de una ontología social (con consecuencia en la concepción de la historia) y en el de la conformación de los sujetos políticos (con implicancias en las luchas sociales). Ambas se vinculan al cuestionamiento de la dialéctica. Nuestro propósito es mostrar que el planteo que hace Laclau de la dialéctica, en el marco de una crítica del determinismo y del esencialismo adjudicado al marxismo, le impide avanzar en una teorización de la negatividad que sería consistente con su proyecto teórico político.

La hipótesis de lectura que guía este trabajo es que Laclau abandona la dialéctica por su carácter determinista y teleológico debido a una particular concepción atribuida a Hegel y a Marx por algunos autores que median la recepción, fundamentalmente Louis Althusser y Lucio Colletti. No obstante, a fines de resolver algunos de los problemas teóricos que el propio autor plantea, es posible recuperar la dialéctica desprendida de una idea de resolución necesaria (como

\footnotetext{
${ }^{9}$ Laclau, Ernesto, and Chantal Mouffe. "Hegemonía y Estrategia socialista; Hacia una radicalización de la democracia. Buenos Aires FCE. 2004, p.13

${ }^{10} \mathrm{La}$ acusación de que Laclau niega la lucha de clases se encuentra entre los mitos más difundidos. Al respecto el autor es explícito: "Por eso mismo la "lucha de clases" no puede darse por sentada como

la forma necesaria que deba asumir la conflictualidad social. La pregunta previa y más fundamental es: ¿hasta qué punto los enfrentamientos colectivos que construyen la unidad de las posiciones de sujeto de los agentes sociales constituyen a estos últimos como clases? La respuesta será evidentemente distinta en cada caso específico" (Laclau, 2000, Op. Cit. p.54), esta idea no está lejos de la concepción de autores marxistas como E.P. Thompson.

${ }^{11}$ Laclau no trabaja la teoría del valor (ni el lugar del trabajo como producción de vida), es decir soslaya una categoría clave de Marx como "trabajo-vivo" que -creemos- sería fundamental para su teoría del discurso como "producción de sentido" (y que tensionaría, desde allí, la distinción entre valor de uso y valor de cambio aportándole elementos de un historicismo radical). En segundo lugar una consecuencia del rechazo a la filosofía de la historia imputada al marxismo: el rechazo a la unidad orgánica bajo la lógica del capital o la subsunción de la vida (la naturaleza y la humanidad) al capital.
} 
reconciliación ${ }^{12}$ ) y vinculada al juego abierto (y contingente) entre negatividad constitutiva y positividad precaria-necesaria. Esto implica escindir negatividad de reconciliación necesaria y de contradicción lógico-formal para replantear la relación de contingencia y determinación subvirtiendo esa dicotomía ${ }^{13}$. En la sección siguiente revisaremos la presencia de Hegel en la obra de Laclau para luego avanzar en el lugar que la dialéctica podría tener en una teoría política contemporánea que sirva para conceptualizar los procesos históricos abiertos incluso en un terreno "pos"marxista o posfundacional.

\section{La muerte de la dialéctica en el olvido de Hegel}

La relación de Laclau con la dialéctica ha sido un aspecto poco explorado ${ }^{14}$, sin embargo este abandono es uno de los principales rasgos del posmarxismo con respecto al marxismo. Para Laclau, Hegel y Marx comparten una lógica ontológica ${ }^{15}$ que, si bien posee diferente contenido, conduce a un cierre de la historia y, en definitiva, un determinismo inaceptable. En sus palabras

Es desde este punto que tenemos que comenzar nuestra consideración de la tradición marxista, ya que en la raíz de ésta hay un discurso anclado en la teleología hegeliana. Conocemos las características que definen esto último: las determinaciones esenciales de cualquier entidad se encuentran en su especificidad conceptual, las contradicciones conceptuales inherentes a esta especificidad nos obligan a movemos hacia una nueva entidad encarnando un nuevo estadio conceptual, etc. Marx no cambió en absoluto las cosas con su 'inversión' de la dialéctica hegeliana: si el fundamento es 'materia' en lugar de 'idea', pero la materia tiene leyes internas de movimiento que son conceptualmente especificables, el materialismo de Marx es tan idealista como el de Hegel. Ontológicamente hablando no son, en realidad, diferentes el uno del otro ${ }^{16}$.

Hablar de dialéctica es hablar de unos de los conceptos más discutidos del marxismo y de una tradición filosófica que se remonta a los eleatas pasando por Heráclito, Platón, Aristóteles y, por supuesto, Hegel. En el campo específico del marxismo y de la filosofía política las controversias sobre su status ontológico o metodológico han generado miles de intervenciones de distinta índole y con distinto rigor. Ahora bien, como argumentamos, el abandono de la dialéctica por parte de Laclau opera en el terreno de la reacción contra el determinismo y la metafísica de la presencia, es decir, en el terreno ontológico. Para Laclau

\footnotetext{
12 Laclau, siguiendo una interpretación tan extendida como objetada, refiere a la dialéctica como un proceso sintético "La dialéctica de Hegel fue un intento fallido de proveer una síntesis capaz de reintegrar estos dos momentos polares a una unidad" (Laclau, Ernesto, La Razón populista, Buenos Aires. FCE. 2005, p. 302).

${ }^{13}$ Nuestro objetivo, por lo tanto, no es contrastar la interpretación de Hegel con lo que Hegel realmente dijo (o con otras interpretaciones de Hegel), como si exigiéramos una especie de primacía exegética sino indicar posibles caminos para abordar los tópicos que interesan en la teoría posfundacional, fundamentalmente una ontología social y una teoría de las identidades políticas en el camino de estudiar procesos políticos.

${ }^{14}$ Entre los trabajos que se ocupan específicamente del asunto podemos contar Muñiz, Marcelo, y María José Rossi. "El fantasma del populismo a la luz de otro fantasma: Laclau lector de Hegel." VIII Jornadas de Sociología de la UNLP (La Plata, 2014$) .2014$. ${ }^{15}$ Hay otra dimensión que el concepto de dialéctica ha operado en la tradición crítica: como método. Esto es relevante por la discusión sobre la teoría de Laclau y (la ausencia de) método. Al respecto: Howarth, David. "Aplicando la teoría del discurso: el método de la articulación." Studia politicae 5 (2012): 37-88, y Glynos, Jason, et al. "Discourse analysis: Varieties and methods." ESRC National Centre for Research Methods Review paper." 2009.

${ }^{16}$ Laclau, Ernesto. "La articulación y los límites de la metáfora." Studia Politicae 20 (2010): p. 30.
} 
Mientras que el marxismo clásico fijaba un sentido objetivo de la historia, que operaba subsecuentemente como horizonte trascendental incuestionado en el análisis de los procesos sociales concretos, lo que nosotros intentamos hacer es historizar el horizonte mismo, mostrar en él su radical contingencia, lo que sólo es posible en la medida en que la radicalización de la interrogación abra la posibilidad de contingencias diferentes. Lo que se requiere, entonces, es dar un paso atrás e inscribir la teoría marxista dentro de un horizonte de interrogaciones más amplio que - sin negar a aquella en su totalidad relativice e historice sus categorías y, sobre todo, nos permita también pensar un conjunto de posibilidades históricas diferentes de aquellas que resultan pensables dentro del marxismo. ${ }^{17}$

Laclau (y Mouffe) evoca a Hegel en casi todos sus trabajos. En HyES lo introduce para tratar el problema de la articulación de elementos en el contexto de la teoría de la hegemonía cuando se predica como concepto ontológico ${ }^{18}$. El problema a tratar es la pérdida de fundamento del orden social con la muerte de Dios y el intento de erigir otros mitos configuradores de la sociedad. Si la Ilustración proponía el recurso de la razón, a partir de la crisis de la concepción del cosmos como unidad orgánica como consecuencia de las tensiones disgregantes del liberalismo y el capitalismo hacia el siglo XVIII-XIX, la generación romántica pudo reinscribir los problemas clásicos de la libertad y de la necesidad en un nuevo contexto histórico. Sin embargo, la evidencia de la ausencia del fundamento necesario (de allí la idea de pensamiento postfundacional) obligó a pensar los nuevos fundamentos y la legitimidad del orden del cosmos (natural y político) pero esta vez como producción humana, citemos in extenso a Laclau en un claro pasaje:

Ahora bien, todo depende de cómo se conciba esta «organización que seamos capaces de darnos a nosotros mismos», que reconduce los fragmentos a una nueva forma de unidad: o bien esa organización es contingente y, por tanto, externa a los fragmentos, o bien tanto los fragmentos como la organización son considerados como momentos necesarios de una totalidad que los trasciende. Es claro que sólo la primera forma de «organización» puede ser considerada como articulación.; la segunda es, en el estricto sentido del término, una mediación. Pero está claro también que las distancias entre una y otra se han presentado en los discursos filosóficos, más que como una clara divisoria de aguas, como una nebulosa zona de ambigüedades.

Esta es la ambigüedad que, desde nuestra perspectiva actual, presenta el pensamiento de Hegel en lo que se refiere a la dialéctica entre unidad y fragmentación. Su obra constituye el momento más alto del romanticismo alemán y, a la vez, la primera reflexión moderna acerca de la sociedad —si entendemos a esa modernidad en un sentido preciso, posiluminista: no una crítica de la sociedad a partir de la utopía, ni una descripción y teorización de los mecanismos que hacen posible un orden que se acepta como cierto y dado; sino una reflexión que parte de la opacidad de lo social respecto a aquellas formas elusivas de racionalidad e inteligibilidad, que sólo es posible detectar refiriéndonos a una astucia de la razón que reconduce la separación a unidad. Hegel aparece así ubicado en la divisoria de aguas entre dos épocas. En un sentido es el punto más alto del racionalismo: el momento en que éste intenta abarcar en el campo de la razón, sin dualismos, la totalidad del universo de las diferencias. La historia y la sociedad tienen, por tanto, una estructura racional e inteligible. Pero, en un segundo sentido, esta síntesis presenta todas las semillas de su

${ }^{17}$ Laclau, 2000, Op. Cit., p. 173

${ }^{18}$ Retamozo, Martín. "Tras las huellas de Hegemón. Usos de hegemonía en la teoría política de Ernesto Laclau." Utopía y praxis Latinoamericana 16.55 (2011). 
disolución dado que la racionalidad de la historia sólo ha podido ser afirmada al precio de reintroducir la contradicción en el campo de la razón.

Bastará pues tan sólo con mostrar que esta última es una operación imposible, que sólo puede verificarse al precio de una constante violación del método que ella misma postula — como lo mostró ya en el siglo XIX Trendelenburg - para que el discurso hegeliano comience a presentarse como algo muy diferente: como una serie de transiciones contingentes y no lógicas. Es aquí, precisamente, donde reside la modernidad de Hegel: ninguna identidad es, para él, positiva y cerrada en sí misma, sino que se constituye como transición, relación, diferencia. Pero si dichas relaciones han dejado de ser relaciones lógicas; si, por el contrario, son transiciones contingentes, en ese caso la conexión entre las mismas no puede ser fijada como momento de una totalidad subyacente o suturada. Es decir, que se trata de articulaciones. En la tradición marxista, esta zona de ambigüedad se muestra en los usos discursivos contradictorios que se han hecho del concepto de «dialéctica» ${ }^{19}$.

Laclau recupera la contribución hegeliana para pensar el problema de la constitución del orden, la introducción de la contingencia y cuestiona la herencia de la dialéctica que de Hegel -a su juiciotomará Marx. Ahora bien, en HyES no hay citas directas de Hegel, y dos son las mediaciones que utiliza Laclau para -vía Marx- aproximarse a Hegel: Louis Althusser y Lucio Coletti. Cada uno de los autores es un vehículo para tratar dos problemas teóricos cuya distinción analítica conviene tener presente: la cuestión de la totalidad social (el orden social) y la cuestión de los sujetos (y el antagonismo). La lógica que subyace al tratamiento es la misma y está orientada por decisiones teóricas que buscan romper con el esencialismo (tanto de la sociedad como de las identidades). Siguiendo a Althusser, y por supuesto no es una interpretación exclusiva del filósofo francés, Laclau le endilga a Hegel la idea de una totalidad compleja que se autodespliega (y por lo tanto contiene la necesidad de una teleología sintetizada en la "astucia de la razón" ${ }^{20}$ ). El concepto de sobredeterminación que Althusser toma de Freud, por el contrario, ofrecerá una la posibilidad de pensar una "formación social" (in)determinada (o sobredeterminada) y abierta al juego de la articulación contingente. Lo que le interesa recuperar a laclau, a partir y más allá de Althusser acertadamente a nuestro criterio- es la posibilidad de superar una versión determinista del marxismo que se radicalizará en el posestructuralismo (al abandonar la "determinación en última instancia"). La imposibilidad de fijar una estructura a priori y/o última abre la posibilidad de pensar la conformación contingente de la sociedad (y también de los agentes) como una construcción discursiva (en el sentido específico que le da Laclau: como articulación de elementos ${ }^{21}$ ). La conclusión que extrae el autor es relevante en términos teóricos: introducir la contingencia implica asumir el problema de la libertad humana y un historicismo radical en la formación social (lo que no significa, como veremos, indeterminación histórica). El problema quizás- es el relativo poco trabajo de la noción de contingencia, su lugar en la teoría política y su relación con la idea de necesidad (y de determinación). En este terreno, Hegel opera como un

\footnotetext{
${ }^{19}$ Laclau y Mouffe, 2004, Op. Cit., p. 158-159

${ }^{20}$ Laclau hace repetidas alusiones a "la astucia de la razón en Hegel" (Laclau, 2005, Op. Cit., p. 111) para referir a la lógica de la necesidad.

${ }^{21}$ Esta noción de discurso, como categoría ontológica, ligada a la articulación ha sufrido desplazamientos hacia una teoría óntica ligada la significación, la retórica y, equívocamente, al lenguaje. El problema -en parte- lo origina el propio Laclau cuando elije ejemplos de significantes como "Solidaridad" en Polonia y luego afirma que no puede reducirse discurso a texto escrito u oral. La mayoría de los estudios inspirados en la teoría del discurso de Laclau, por su parte, se ocupan de analizar intervenciones de líderes, es decir reducen el discurso a una de las dimensiones de la práctica significativa.
} 
"lugar común" determinista, idealista y teleológico cuya concepción se filtra en el marxismo como una sombra y de la que es necesario escapar. Carlos Pérez Soto cuestiona directamente el planteo y sostiene

Al no hacer nunca la diferencia entre Hegel y las versiones soviéticas del hegelianismo Laclau produce la desafortunada confusión de criticar en Hegel lo que se podría criticar de manera legítima en la filosofía soviética. Y llega, en esta línea, a cometer el abuso, ya consagrado por Popper, de citar la filosofía soviética cuando quiere criticar a Hegel. Cuando se examina, en sus textos, cómo critica la filosofía hegeliana lo que encontramos es una argumentación basada completamente en Della Volpe y en Colletti, e incluso en los desafortunados textos popperianos. ${ }^{22}$

La influencia de Galvanno Della Volpe ha sido reconocida por Laclau, aunque también el "exagerado optimismo" que le generó inicialmente sus argumentos contra la dialéctica. En este sentido afirma "una filosofía idealista como la de Hegel, que reduce lo real al concepto, pudo concebir los antagonismos como contradicciones; pero, como señaló la escuela dellavolpiana en Italia, es incompatible con una filosofía materialista como el marxismo que afirma el carácter extra mental de lo real" 23 . En su teoría del antagonismo, Laclau sigue la crítica de los dellavolpianos -especialmente de Colletti- a la contradicción dialéctica pero se aparta de sus conclusiones $^{24}$. El antagonismo no es ni una relación dialéctica ni una relación de oposición real (ya que no implica la relación entre términos positivos) sino que es el modo en que la imposibilidad de la plenitud se presenta ${ }^{25}$. En un texto puente entre Laclau, Ernesto. Politics and ideology in Marxist theory ${ }^{26}$ y $H_{y} E S^{27}$, Laclau había homologado contradicción y antagonismo, pero en $H y E S$ corrige esa cuestión para proponer al antagonismo como una relación que no se subsume ni como contradicción ni como oposición real (las figuras que Colletti toma de Kant). Sigamos el argumento:

Colletti parte de la distinción kantiana entre oposición real (Realrepugnanz) y contradicción lógica. La primera coincide con el principio de contrariedad y obedece a la fórmula «A-B»: cada uno de sus términos tiene una positividad propia, independiente de su relación con el otro. La segunda es la categoría de contradicción y obedece a la fórmula «A-no A»: la relación de cada término con el otro agota la realidad de ambos. La contradicción tiene lugar en el campo de la proposición; sólo a un nivel lógico-conceptual podemos incurrir en contradicciones. El primer tipo de oposición, en cambio, tiene lugar en el campo de los objetos reales, ya que ningún objeto real agota su identidad en su oposición a otro objeto, sino que tiene una realidad propia, independientemente de aquélla. De ahí Colletti concluye que si Hegel, en tanto filósofo idealista que reducía la realidad al concepto podía introducir la contradicción en el seno de lo real, esto es

\footnotetext{
${ }^{22}$ Pérez Soto, Carlos “Adversus: Foucault-Laclau-Bataille-Benjamin”. UARCIS: Santiago de Chile., 1997, p. 32. La reflexión de Perez Soto se produce luego de las conferencias de Laclau en Santiago de Chile (1997), allí el autor chileno interviene en la ronda de preguntas con señalamientos, en particular, sobre el status de la "dislocación". Luego, en el libro Sobre Hegel, Perez Soto dedica punzantes notas críticas a la concepción que Laclau tiene sobre el pensamiento hegeliano.

${ }^{23}$ Laclau, Ernesto. "Ideología y posmarxismo." Anales de la educación común (2006), p. 2

${ }^{24}$ Laclau y Mouffe, 2004, Op. Cit. Laclau Laclau, Ernesto “Antagonismo, subjetividad y política”. En: Debates y Combates, Año

2, no. 3. 2012. p.7-37

25 Ver al respecto: Retamozo, Martín, y Soledad Stoessel. "El concepto de antagonismo en la teoría política contemporánea." Estudios Políticos 44 (2014): p. 13-34.

${ }^{26}$ Laclau, Ernesto. Politics and ideology in Marxist theory... Op. Cit.

${ }^{27}$ Laclau, Ernesto "Populist Rupture and Discourse", Screen Education, 34, 1980, p. 87-93
} 
incompatible con una filosofía materialista como el marxismo, que parte del carácter extramental de lo real. Los marxistas pues, habrían incurrido en una lamentable confusión al considerar los antagonismos como contradicciones. ${ }^{28}$

Ahora bien, ¿cuál es la relación entonces entre contradicción, antagonismo y dialéctica? Laclau se aparta de Marx -y por transposición de Hegel- refiriendo el tratamiento de la cuestión en dos textos canónicos del marxismo: El Manifiesto Comunista y el Prólogo del 59. En el primero la relación se da entre las clases, en la segunda la relación es entre relaciones sociales de producción y fuerzas productivas ${ }^{29}$. La lucha de clases puede comprenderse como antagonismo sin contradicción (ya que no hay nada al interior de la relación compra y venta de la fuerza de trabajo inherentemente contradictoria), mientras que en la segunda existe una contradicción, pero no necesariamente un antagonismo. Nos interesa aquí, por lo tanto, la idea de contradicción (tanto formal como dialéctica).

La concepción hegeliana de la contradicción subsumía en ella tanto a los antagonismos sociales como a los procesos de cambio natural. Esto era posible en la medida en que la contradicción era concebida como momento interno del concepto; la racionalidad de lo real era la racionalidad del sistema: todo "exterior" respecto del mismo estaba, por definición, excluido. En el antagonismo tal como lo concebimos nos encontramos, por el contrario, con un "exterior constitutivo". Es un "exterior" que bloquea la identidad del "interior" (y que es a la vez, sin embargo, la condición de su constitución $)^{30}$.

El ataque a la dialéctica es uno de los puntos centrales del pos-marxismo. Para ello es necesario una primera operación que prepara el terreno para la crítica: reducir la contradicción dialéctica a la lógica formal (de predicados). En efecto, es absurdo sostener que la realidad histórica pueda pensarse bajo una idea estricta de contradicción del tipo A y noA, pero de eso no se sigue la impugnación a la contradicción dialéctica. Para Laclau:

"contradicción" en su sentido dialéctico es totalmente incapaz de capturar lo que está en juego en un antagonismo social. B puede ser -dialécticamente- la negación de A, pero sólo puedo moverme hacia B mediante el desarrollo de algo que ya estaba contenido, desde su mismo comienzo, en A. Y cuando A y B son Aufbehoben en C, podemos ver aún más claramente que la contradicción es parte de una secuencia dialéctica que es completamente determinable por medios conceptuales ${ }^{31}$.

El problema, claro está, es qué se entiende por contradicción dialéctica. Si ésta cae bajo el esquema A y noA la crítica sería adecuada, pero si la idea de dialéctica no se puede enunciar bajo la idea de una contradicción formal, ni bajo el equívoco esquema de tesis-antítesis-síntesis ${ }^{32}$ nos encontramos en otro terreno. El esquematismo dialéctico está, seguramente, lejos de la

\footnotetext{
${ }^{28}$ Laclau y Mouffe, Op. Cit., p. 211

${ }^{29}$ Tempranamente Žižek criticó la idea de antagonismo en Laclau desde una perspectiva lacaniana.

${ }^{30}$ Laclau, 2000, Op. Cit., p. 33

${ }^{31}$ Laclau, 2005, Op. Cit., p. 112

${ }^{32}$ En el notable Hegel Myths and Legends. (1996) compilado por Jon Stewart se revisa el mito de la renuncia hegeliana al principio de no contradicción alimentado por la filosofía anglosajona desde Bertrand Russell hasta Mario Bunge al respecto pueden consultarse los capítulos de Robert Pippin y Robert Hanna. También puede verse Jameson, Frederic,. Valencias de la dialéctica. Eterna Cadencia Editores, 2013.
} 
concepción del propio Marx. Sin embargo, es mucho más relevante preguntarnos si podemos sostener la dialéctica allende de lo que hayan dicho Hegel y Marx. Y en ese caso ¿qué dialéctica? Más allá de hacer justicia con la (in)justa crítica de Laclau a Hegel, nos interesan más las ideas que se desprenden que un acto de filología y exégesis. No obstante, conviene anotar, que afirmar que concepto y la Idea en Hegel se pueden reducir a una dicotomía materialidad/mentalidad es, cuando menos, una reducción cuestionable (quizás de origen feuerbachiano). Los teóricos del marxismo aún nos deben una respuesta consistente a esta cuestión de qué se entiende por contradicción (dialéctica) sin apelar a las fórmulas dogmáticas. El punto de apoyo para la reconceptualización de la dialéctica lo encontramos en el lugar de la negatividad. Dice Laclau:

tenemos una noción de negatividad que no se relaciona con la dialéctica. No es dialectizable porque para serlo tendríamos que mostrar que hay una necesidad objetiva, interna en el evento de la dislocación, que genera, necesariamente, una y sólo una respuesta posible. Pero todavía, en ese argumento, había un resabio dialéctico, que es el que traté de eliminar en Nuevas reflexiones sobre la revolución de nuestro tiempo. El resabio dialéctico era la suposición que la dislocación social era directamente un antagonismo, es decir que una vez que hay dislocación social, ésta va a ser vivida por los agentes sociales como relación antagónica, pero esto no es necesariamente el caso ${ }^{33}$

Laclau busca preservar algo de la dialéctica (la negatividad) y prescindir de otro de los elementos frecuentemente asociado a ella, la -supuesta- resolución necesaria. En las NRR prosigue:

La noción de 'negatividad' en que nuestro análisis se funda no es la negatividad en el sentido dialéctico del término. La noción hegeliana de negatividad es la de una negatividad necesaria; es decir, que lo negativo es un momento en el despliegue interno del concepto y que está destinado a ser reabsorbido en una Aufhebung — es decir, en una unidad superior. No es aquí ni siquiera necesario, como a veces se ha sostenido, que el último término del movimiento dialéctico sea positivo; incluso si el Sistema es concebido como movimiento sin resolución entre positividad y negatividad, esta última es siempre interna al sistema. La propia contingencia es absorbida como momento en el autodespliegue de lo necesario ${ }^{34}$.

Es evidente que si Hegel afirmó el panlogismo como una reducción del ser al concepto (y si el concepto se refiere al pensamiento y el ámbito estrictamente mental) su esfuerzo no mercería el lugar que tiene en la historia de la filosofía. Ahora bien, si es posible pensar con Hegel el ser como historicidad de la humanidad en despliegue, como despliegue de la libertad y la razonabilidad, entonces estamos frente a otro horizonte. La Fenomenología del Espíritu (1966/2011), en una lectura posible, es el intento de abordar el desafío de pensar la experiencia de la libertad y de la comunidad. El saber Absoluto implica, de algún modo, el intento (y con Laclau podemos decir: "necesario e imposible") de constituir una comunidad con la libertad como condición de posibilidad. De allí que Hegel haya sido reivindicado por vertientes comunitaristas en la filosofía política contemporánea como la de Charles Taylor ${ }^{35}$ y también como el primer postmarxista tal como lo hace Žižek ${ }^{36}$. No obstante, Laclau le reconoce a Hegel

${ }^{33}$ Laclau, Ernesto. "Hegemonía y Antagonismo; el imposible fin de lo político." Santiago de Chile: Cuarto Propio , 2002 , p. 94

${ }^{34}$ Laclau, 2000, Op., Cit., p. 43

35 Taylor, Charles, Hegel. Cambridge University Press. 1975

36 Žižek, Slavoj, El sublime objeto de la ideología. Buenos Aires, Siglo XXI, 1992 
esta idea de la necesidad de un límite, aunque a su juicio “externo", momentáneo y no constitutivo:

For Hegel, for example, the perception of a limit was the perception of what is beyond it; the limit, then, lies within the conceivable. Structuralism's radical relationalism would thus be subsumable under the category of the infinite regress. This point could be generalized: the most diverse forms of contemporary thought are permeated by the relational character of identities in conjunction with the impossibility of intellectual mastery over the contex ${ }^{37}$

No obstante, la negatividad en el pensamiento hegeliano también se encuentra en el terreno ontológico tan relevante para el posestructuralismo. En efecto, es la inscripción de la nada en el ser (una negatividad constitutiva) la que es mediada en el devenir de la historia humana y que tiene que ser llenada en un paso de la contingencia a la determinación. Una lectura posfundacional de $\mathrm{Hegel}^{38}$ (y más allá de Hegel) es consistente con su intento postilustrado de abordar los procesos históricos bajo una concepción de la historia que incorpora la negatividad y el juego incesante de llenar el vacío constitutivo (de la sociedad y de las identidades sociales)

Hay aquí una ambigüedad, y yo diría que ella ha estado presente desde la misma prehistoria del marxismo, es decir, desde el pensamiento hegeliano. Por un lado, el hegelianismo hace de la negatividad el elemento constitutivo de toda identidad - la imposibilidad de toda identidad de "descansar" en sí misma. Pero, por el otro lado, este movimiento de lo negativo no implica ninguna contingencia, dado que él encuentra su identidad lineal en el sistema ${ }^{39}$

Slavoj Žižek ${ }^{40}$ ha sido, en muchas de sus intervenciones, un defensor de Hegel frente a las referencias de Laclau, al punto que éste le dedica el punto II. Bajo el título de "Hegel"41 En esos diálogos con Žižek y Judith Butler, Laclau reconoce que ambos autores se han unido en su contra para defender a Hegel (tanto como él se ha unido a Butler para defender la deconstrucción contra Žižek, y con Žižek para defender a Lacan contra los argumentos de Butler).

Žižek acusa a Laclau de un giro antihegeliano "demasiado rápido" 42 y Laclau contesta "No puedo simplemente descartar la lectura que Žižek hace de Hegel, por dos razones. Primera, porque estoy de acuerdo con casi todo lo que él extrae de los textos de Hegel. Segundo, porque no pienso que

\footnotetext{
${ }^{37}$ Laclau, Ernesto "Politics and the limits of modernity" Social Text, (21), 1989, p. 69-70

${ }^{38}$ Realizar una lectura postfundacional de Hegel no implica considerarlo "el primer post-marxista" como lo hace Žižek aunque el giro es verdaderamente ocurrente. No obstante, cabe señalar que en el párrafo seguido al que lanza la humorada reconoce que la concepción de la sociedad atravesada por un antagonismo constitutivo es el gran mérito de Laclau y Mouffe

${ }^{39}$ Laclau, Ernesto, 2000, Op., Cit., p.215

${ }^{40}$ Žižek, por supuesto, es el gran hegeliano de la filosofía política contemporánea. Su herética y siempre provocadora lectura de Hegel (junto con la de Lacan) consta en casi toda su obra. Aquí solo citaremos uno de sus últimos libros Less than nothing: Hegel and the shadow of dialectical materialism. En el debate con Laclau, Žižek defiende la noción hegeliana de "universal concreto" para pensar la relación (im)posible entre lo particular y lo universal que constituye el corazón de la categoría de hegemonía en Laclau. El debate entre ambos pensadores tuvo un capítulo en Contingencia, Hegemonía y Universalidad (2003) junto a Judith Butler, y luego sucesivos debates entre los años 2005 y 2006.

${ }^{41}$ Laclau, Ernesto "Identidad y hegemonía: el rol de la universalidad en la construcción de lógicas políticas", in: Laclau, Žižek \& Butler. Contingencia, hegemonía y universalidad. Buenos Aires, FCE, 2003a., pp. 49-94

${ }^{42}$ Weimar (2013) en la misma línea le objeta a Laclau tirar el niño con el agua sucia. Weiman, Javier. "Dialéctica y ontología: Repensando el antagonismo posmarxista desde la Teoría Crítica." Constelaciones. Revista de Teoría Crítica 5 (2013): 280-310.
} 
él este proyectando en esos textos una serie de consideraciones ajenas a los textos mismos, sino que se aplican perfectamente a dichos textos"43. No obstante, Laclau se aparta de Hegel en dos aspectos. El primero -allí aparece una primera cita de la Lógica- ataca a Hegel por su reflexión sobre el lenguaje. Es francamente extraño que de una reflexión sobre la distinción entre el lenguaje común y el lenguaje filosófico Laclau extraiga conclusiones sobre el lugar de la retórica en su teoría frente a un lugar del lenguaje en la teoría hegeliana. No podemos pensar esto sino como un síntoma de un necesario desplazamiento del discurso al lenguaje para incluir a la retórica, lo que podemos considerar un retroceso sobre la noción de discurso, que no sólo produce sentido, sino que instituye condiciones de posibilidad para la acción tal como afirma una teoría materialista del discurso. Esto no implica soslayar la retórica sino reubicarla y, consecuentemente, desprenderla de su función ontológica, es decir del "fundamento retórico de la sociedad" tal como se titula el libro póstumo de Laclau (aunque, por supuesto, tropos retóricos nos ayuden a comprender lógicas de constitución de lo social). El segundo aspecto que destaca el autor es el rechazo a la distinción entre forma y contenido (tal como, invocando a Hegel, propone Butler) y que luego ahondará el desacuerdo en torno al concepto de universalidad concreta (o lo abstracto concreto) $)^{44}$

Ahora bien, aunque puede concederse que la mayoría de los usos de "dialéctica" en pretendidos marxistas son imprecisos (se asemejan más a una idea de complejidad, de inter-relación o de conflictividad sin ahondar en la definición de contradicción y de negatividad) de eso no se deriva que hay que abandonar el concepto $\mathrm{y}$, menos aún, que eso es lo que tenga en derivarse necesariamente de los textos de Hegel. Laclau, ante la objeción de Carlos Perez Soto recogida en las intervenciones de sus conferencias en Chile antes citada, responde:

Respecto a Hegel, este es un problema evidentemente de lectura. En Hegel hay una dualidad, por un lado, nosotros vemos el sometimiento de todo contenido concreto al principio de una racionalidad que lo funda, por otro lado, por el hecho mismo de que la racionalidad se extiende a tantos contenidos concretos, la racionalidad misma empieza a teñirse por contenidos, por la concreción de estos contenidos y empieza a hacer algo que va más allá de sí misma. Todas las lecturas de Hegel están dominadas por una u otra de este tipo de lecturas, o bien se ve en Hegel el predecesor del marxismo y el predecesor de una concepción existencialista de la historia, o bien se ve en Hegel el primero de los post-marxistas. Yo he tomado una línea en mi lectura de Hegel, que tiende a subrayar el carácter racionalista del sistema hegeliano, llamado panlogicismo, hay otros autores, por ejemplo Slavoj Žižek, que ven en Hegel una prefiguración de Lacan y del pensamiento del carácter indeterminado de las identidades ${ }^{45}$

${ }^{43}$ Laclau, Ernesto, 2003 a, Op., Cit., p. 67.

${ }^{44}$ Laclau, Ernesto, "Estructura, historia y lo político", in: Laclau, Žižek \& Butler. Contingencia, hegemonía y universalidad. Buenos Aires, FCE, 2003b., p.193

${ }^{45}$ Laclau, 2002, Op. Cit., p.148 


\section{Dialéctica, negatividad y la búsqueda de la positividad perdida}

En la obra de Laclau pueden identificarse tres problemas en las que su arsenal teórico opera: la constitución de la sociedad (ontológico), la conformación de los agentes sociales (identitario) y la lógica en el campo de la política (estratégico). Esto es visible particularmente en el uso que hace de la categoría hegemonía, populismo y antagonismo las cuales también utiliza para abordar problemas diferentes referidos a la constitución de la sociedad, la formación de las identidades y la dinámica de la política. Los tres niveles, y las reflexiones en torno a ellos, se contaminan. Esto ha producido un desplazamiento equívoco en los conceptos. No obstante, es clave integrar estas dimensiones en una teoría política que tiene consistencia en el pensar los modos de construcción del orden, cómo se disputa su institución y los agentes que lo realizan. Como mostramos en este artículo, el (des)encuentro con Hegel y la dialéctica opera fundamentalmente en el terreno ontológico $^{46}$ al objetar un supuesto teleologismo inmanente. Sin embargo, este movimiento teórico afecta a los otros terrenos ya que, en definitiva, si no hay lugar para la contingencia de lo político, entonces no tiene sentido pensar la conformación de los sujetos políticos como una tarea histórica y política.

En este contexto, restituir la dialéctica es clave para un movimiento integrador a la hora de vincular el planteo ontológico posfundacional con una teoría que ayude a comprender la configuración de sujetos sociales y sus luchas. La recuperación de la dialéctica en el pensamiento político posfundacional no radica en la nostalgia de un concepto caro a la tradición política emancipatoria sino en su valor para pensar los procesos de configuración del orden social y las luchas emergentes. Esta recuperación viene de la mano de la idea de negatividad, aceptada por Laclau, pero poco desarrollada en su obra. Por lo tanto, escindir la negatividad del orden de su resolución necesaria será una clave para nuestro propósito. Veamos cómo opera la negatividad en el posestructuralismo ${ }^{47}$.

En la teoría política que venimos tratando existe una doble inscripción de la nada. Por un lado, como ausencia (de fundamento) que permite hablar de una teoría política posfundacional ${ }^{48}$. La ausencia de fundamento implica concebir que los fundamentos del orden no pueden concebirse a priori (tesis teórica) y que cualquier intento de postular fundamentos trascendentes niega la democracia (tesis ético-política). La concepción de una nada constitutiva del ser, es claramente de inspiración hegeliana. Dice Hegel En La Ciencia de La lógica ${ }^{49}$

Todavía no es nada y tiene que devenir algo. El comienzo no es la nada pura, sino una nada de la cual tiene que surgir algo; luego también el ser está ya contenido en el comienzo. El comienzo contiene, en consecuencia, a ambos: el ser y la nada; es la unidad del ser y la nada; es decir, es un

\footnotetext{
${ }^{46}$ A diferencia de Marx, en el que uno de los usos de la dialéctica se relaciona con el método, en el caso de Lacalu la reflexión epistemológica y metodológica es marginal.

${ }^{47}$ Un excelente estudio sobre la relación de la dialéctica (y la negatividad) con otros autores del post-marxismo puede encontrarse en Grant, J. Dialectics and contemporary politics: Critique and transformation from Hegel through post-Marxism Routledge: New York-London, 2011.

${ }^{48}$ Marchart, Oliver. Post-Foundational Political Thought: Political Difference in Nancy, Lefort, Badiou and Laclau: Political Difference in Nancy, Lefort, Badiou and Laclau. Edinburgh University Press, 2007.

${ }^{49}$ La Ciencia de la Lógica es uno de los textos de Hegel citado por Laclau (2005, Op. Cit., p. 178 y 2003a, Op. Cit., p. 68)
} 
no-ser que al mismo tiempo es ser, y un ser, que al mismo tiempo es no-ser. Además: el ser y la nada existen en el comienzo como diferentes; pues el comienzo señala algo distinto; es un no-ser, que se refiere al ser, como a un otro; lo que comienza no existe todavía; sólo va hacia el ser. El comienzo, en consecuencia, contiene el ser como algo que se aleja del no-ser o lo elimina, es decir, como un contrario del no-ser. Pero, por otra parte, lo que comienza ya existe, pero simultáneamente todavía no existe. Los contrarios, ser y no-ser, están por tanto en el comienzo en una unión inmediata; es decir, que el comienzo es su unidad indiferenciada. ${ }^{50}$

Ahora bien, si el posfundacionalismo no es una teoría antifundacional es porque no niega que ordenar la vida humana requiere de proveer fundamentos (parciales, contingentes, finitos) que pueden ser objeto de disputas diversas puesto que produce y ordena la vida humana (clase, género, étnica, preferencia sexual, etc.). Lo que nos interesa recuperar aquí es la presencia de esa ausencia (de una nada que indefectiblemente hay que llenar) pero cuya aparición óntica admite la pluralidad, incluso aunque esta permanezca latente.

La ausencia de fundamento es, sin embargo, una forma de la positividad y de posibilidad. Hay nada (como ausencia) y esa nada contiene el Ser (la necesidad de un fundamento). Pero también el Ser -como fundamento- contiene esa ausencia (la nada) cuyo llenado es retrospectivo (;Como decía Hegel!) ya que pone sus propios fundamentos). Esa falta es ya una positividad en todavíano para usar el giro de Bloch, es la ausencia de algo que es algo. Como sostiene Groppo siguiendo a Espósito "Es decir, la falta no es puramente negativa, sino que implica una dimensión positiva, su presencia como falta. Ese es el único nivel de positividad que presenta la comunidad, una positividad vinculada y dependiente del hecho de indicar y señalar la falta constitutiva. Esta falta es constitutiva, primordial, precisamente porque no viene a cortar, castrar, prohibir, tachar una plenitud previa, sino que es ella misma previa" ${ }^{51}$

La configuración del orden implica una concepción de la negatividad para generar la positividad (allí tenemos un ejemplo de dialéctica de los contrarios). Producir la vida implica negarla, esto lo detectó Marx con su análisis del trabajo vivo y el plus-valor ${ }^{52}$. Enrique Dussel ha trabajado minuciosamente la idea de una negatividad constitutiva del orden que produce víctimas cuya praxis es el vehículo de emancipación (vía la negación de la negación). En sus términos -y esto lo recupera de Levinas- la totalidad (el orden social) produce exclusiones al negar la vida de parte de la comunidad. El reconocimiento de esa alteridad al orden es la fuente de la analéctica ${ }^{53}$ y el

\footnotetext{
${ }^{50}$ Hegel, G.W.F (Ciencia de la lógica, trad. A. y R. Mondolfo, Solar / Hachette, Buenos Aires, 1968., p.36-37.)

${ }^{51}$ Groppo, Alejandro, "Tres versiones contemporáneas de la comunidad: Hacia una teoría política post-fundacionalista”. Revista de Filosofía y Teoría Política (42), p. 59
}

\footnotetext{
${ }^{52}$ Laclau lo reconoce con respecto a la libertad "Si la libertad sólo puede realizarse a través de su alienación en un contenido externo, proveyéndole de esta manera la determinación que le falta, y si un contenido tal es el principio de organización, este último no puede ser algo meramente objetivo ni, por esta misma razón, meramente subjetivo" Laclau, Ernesto, and Lilian Zac. "(A) notando la brecha: el sujeto de la política." Studia Politicae 31, 2013, p. 6

53 Dice Dussel: "Subsume a la dialéctica y opino que la supera, no es totalizada (puramente ontológica) ni equívoca (como Lévinas), sino que se abre a un ámbito, donde la hiper-potentia relanza el proceso político hacia los actos políticos antihegemónicos y que transforman las instituciones. El «acontecimiento creador» (más allá del mero «acontecimiento» fundacional de A. Badiou) supera el orden vigente y abre el camino hacia el nuevo orden futuro.”, Dussel, Enrique. Política de la liberación: arquitectónica. Editorial Trotta, 2009 p, 38.
} 
principio crítico de acción de las víctimas que legitima su lucha por negar esa negatividad y abrir espacios de devenir-otro del sistema para instituir ordenes que disminuyan la negatividad e incremente la positividad de la vida. En la producción del antagonismo aparece, así, la negación de la negación. El ejercicio de la negatividad productiva sobre los cuerpos y la subjetividad (indistinguibles, como biopoder) es condición de posibilidad de la vida (la biopotentia).

La articulación, en la terminología de Laclau, no es solo la puesta en orden de los elementos preconstituidos sino la genuina producción de relaciones sociales (y, en este sentido, de la vida). La diferencia entre Dussel y Laclaues que el primero tiene la ventaja de partir de una ética de la liberación que le permite distinguir luchas genuinas (de las víctimas) contra luchas por la dominación. El segundo aporta capacidad comprensiva hacia otras luchas, incluso aquellas conservadoras. La negatividad en el pensamiento político posfundacional es necesaria, como condición de producción del orden, pero tanto la negación como aquello que es negado es histórico (sencillamente porque el ser social es histórico y las identidades lo son como lo enunció Marx en la tesis VI sobre Feuerbach). En consecuencia, si siempre hay negatividad es posible pensar en la construcción de demandas de sectores dominantes en la totalidad social que (se) sienten negados en su ser histórico, percibiendo que sus derechos son negados (a vivir en una comunidad jerárquica, a portar armas de fuego, a disponer de las mujeres, de los trabajadores, de poseer esclavos, etc.). También es posible concebir las situaciones en que la propia demandización de la negatividad subalterna construye proyectos de orden conservador (por ejemplo, mayores niveles represivos e implementación de dispositivos de control ante la demanda por seguridad, regímenes teocráticos, etc.). La elaboración de la demanda a partir de una instancia de negatividad (los sentidos para construir una experiencia de negatividad como tal) y el reverso, entendido como proyecto (ya sea autónomo o heterónomo), son construcciones políticas, contingentes e históricamente determinadas. Las acciones constitutivas (que llenan la nada del orden y producen la negación de la negatividad) son históricas. Dice Laclau

Lo que encontramos, por el contrario, es siempre una situación limitada y determinada en la que la objetividad se constituye parcialmente y es también parcialmente amenazada; en la que las fronteras entre lo contingente y lo necesario se desplazan constantemente. Y este doble juego de subversión mutua entre lo contingente y lo necesario es un terreno ontológicamente más primario que el de una objetividad pura o una contingencia total $(,,$,$) "Es en este sentido que lo contingente$ subvierte lo necesario: la contingencia no es el reverso negativo de la necesidad sino el elemento de impureza que deforma e impide la constitución plena de esta última ${ }^{54}$

Ahora bien, nuestra propuesta en este punto es dar un paso más allá, que consiste en ya no considerar que la contingencia subvierte lo necesario sino subvertir esa distinción de modo tal que sea posible indagar la relación constitutiva entre contingencia (que como dice Laclau, empíricamente nunca es absoluta) y determinación. El concepto de contingencia posee un escaso desarrollo en la obra de Laclau y es necesario avanzar sobre este asunto ${ }^{55}$. Desde el punto de vista

\footnotetext{
${ }^{54}$ Laclau, 2000, Op., Cit., p. 44.

${ }^{55} \mathrm{El}$ autor define "Contingente es aquel ser cuya esencia no implica su existencia (...) Afirmar que algo es radicalmente contingente, que su esencia no implica su existencia, equivalente por lo tanto a decir que las condiciones de existencia de una entidad son exteriores a la misma" (Laclau, 2000, Op., Cit., p. 36)
} 
presente, contingencia es el reverso de la idea de determinación-única-necesaria. En el terreno lógico significa admitir que dado un estado de cosas $\mathrm{A}$ no se sigue un estado de cosas $\mathrm{B}$ sin que medien los determinantes que hacen que de la situación A se pase a la situación $\mathrm{B}$ (mediación implica incorporar la temporalidad). En consecuencia, contingencia significa indeterminación a priori más no pura indeterminación. Un evento B sucede porque está determinado por intervenciones que lo hacen B (que lo vuelven necesario ${ }^{56}$ ). Ahora bien ¿Qué estado de cosas B puede seguirse de un estado de cosas A? El desplazamiento está en pensar qué de lo lógicamente posible es históricamente posible o "realmente" posible. Dice Laclau "Y es importante también advertir que las posibilidades reprimidas no son todas aquellas que resultan lógicamente posibles en una cierta situación — es decir, todas aquellas que no violan el principio de contradicción[sino tan] "sólo aquellas que podemos denominar como posibilidades incoadas, aquellas que han tenido un principio de actualización y han sido eliminadas" ${ }^{\prime 57}$. Por la negativa, Laclau introduce el concepto de potencialidad, el problema entonces radica en determinar lo históricamente posible en un determinado momento histórico. Hugo Zemelman ${ }^{58}$ a partir de esta situación desarrolló el concepto de "activación de potencialidades" para la praxis política que interviene en las determinantes del curso de la historia. Lo anterior implica analizar las condiciones de posibilidad de un momento histórico, la potencia condensada y los futuros contenidos (de allí la importancia política del análisis de coyuntura y de la acción política).

\section{Corolario}

La recuperación del pensamiento dialéctico -o al menos de un pensamiento dialéctico- implica repensar la concepción de cómo se pasa de una figura a otra, es decir de la relación constitutiva de, en este caso, contingencia y necesidad ${ }^{59}$. Para ello debemos ubicar la contingencia como constitución ontológica como condición de la determinación histórica (la historia es el resultado del incesante juego de la contingencia y las determinaciones ${ }^{60}$ ). No debe confundirse determinación con determinismo y esto tiene dos consecuencias relacionadas. Por un lado, desplaza el análisis histórico hacia la pregunta por los determinantes que intervinieron para que un acontecimiento suceda ${ }^{61}$. Por otro lado, el análisis político implica en el estudio de los procesos abiertos (dados y dándose) cuyo conocimiento se relaciona con las estructuras y la

\footnotetext{
${ }^{56}$ Un ejemplo: pensemos en un sorteo de Lotería. A priori, que salga, supongamos el 232 de un bolillero de mil posibilidades es contingente. Ya hay una limitante, no puede salir cualquier cosa (un elefante o el 1254), sino una opción entre el 000 y el 999. Ahora bien, luego de que sale la bolilla 232 esta puede considerarse "necesaria" en el sentido que, dado el bolillero, la ubicación de las piezas, el momento exacto de la extracción, etc., es "necesario" que salga ese número. Para los eventos humanos las variables no sólo se multiplican, sino que la libertad de tomar cursos de acción potencialmente infinitos dificulta ponderar las probabilidades e, incluso, lo hace superfluo.

${ }^{57}$ Laclau, 2000, Op., Cit., p. 48

${ }^{58}$ Zemelman, Hugo. Los horizontes de la razón: uso crítico de la teoría. Barcelona, Anthropos Editorial, 1992.

${ }^{59}$ Esta idea es consistente, por ejemplo, con el planteo de Brincat, Shannon en "Negativity and open-endedness in the dialectic of world politics." Alternatives 34.4 (2009): 455-493.

${ }^{60}$ Sobre este punto Laclau indica "El punto de partida del análisis debe ser, por lo tanto, la determinación de aquellos puntos de negatividad que constituyen lo que hemos denominado condiciones de posibilidad y a la vez condiciones de imposibilidad de la objetividad social” (Laclau, 2000, Op., Cit., p. 53)

${ }^{61}$ Algo en esta dirección apunta el propio Laclau "lo que se da en nuestro caso es una peculiar dialéctica entre necesidad y contingencia: puesto que la identidad depende enteramente de condiciones de existencia que son contingentes, su relación con estas últimas es absolutamente necesaria" (Laclau, 2000, Op., Cit., p. 37)
} 
praxis de determinación hacia un horizonte contenido como proyecto. En consecuencia, hay una sutil distinción de la relación entre contingencia y determinación ya sea para el pensamiento histórico y el pensamiento político. El primero se ocupa de indagar las determinaciones que hicieron que un proceso adquiera determinada morfología (aspectos políticos, culturales, económicos, climatológicos, incluido el azar y la decisión ${ }^{62}$ ), el segundo de identificar espacios de activación para la praxis ${ }^{63}$. Los tres campos en que opera la teoría de Laclau (lo político, la política y las identidades políticas), entonces, reencuentran su relación. Las coyunturas las articulan: la conformación de los sujetos (que incluye a las estructuras que los determinan) y la estrategia política se ponen en consonancia con "lo político", es decir, con los modos de producir parcialmente a la sociedad. La dialéctica se constituye en una categoría importante en el andamiaje posmarxista para avanzar en esta cuestión.

En un célebre Epílogo a la segunda edición alemana de El Capital, Marx se había propuesto extraer de la dialéctica hegeliana el núcleo racional que estaba envuelto en el misticismo., Quizás sea hora de desarmar el envoltorio místico con los que muchos marxistas y postmarxistas envolvieron a la dialéctica de Hegel. El pensamiento político posfundacional tiene un horizonte para caminar en esa dirección y replantear la relación entre contingencia, negatividad, determinación y luchas sociales.

\section{Bibliografía}

- Boron, A. (1996). "Postmarxismo"? crisis, recomposición o liquidación del marxismo en la obra de Ernesto Laclau. Revista Mexicana De Sociología, 58(1), 17-42.

- Boucher, G. (2000)," Hegel and Postmodern Discourse Theory," 1-3. Paper presented at the Hegel-Marx-Derrida Seminar, Melbourne 18th February 2000. (disponible en https://www.marxists.org/reference/archive/hegel/txt/gb2000 2.htm)

- Brincat, S. (2009). Negativity and open-endedness in the dialectic of world politics. Alternatives: Global, Local, Political, 34(4), 455-493.

- Butler, J., Laclau, E., Žižek, S. ([2000] 2003). Contingencia, hegemonía y universalidad. Fondo de Cultura Económica. Buenos Aires.

- de Ípola, E. (1979) "Populismo e ideología (A propósito de Ernesto Laclau: 'Política e ideología en la teoría marxista'). En Revista Mexicana de Sociología Vol. 41, No. 3 (Jul. - Sep.,), pp. 925 960 (también en Ideología y discurso populista, Folios, México, 1982)

- de Ípola, E. (1982) “Crítica a la teoría althusserista sobre la ideología” en Ideología y discurso populista, México, Folios

\footnotetext{
${ }^{62}$ Como, por ejemplo, en ese cuento en el que un dictador declaraba guerra a países equivocados sólo por un desconocimiento de geografía y desataba así cruentos procesos "reales".

${ }^{63}$ Es cierto, sin embargo, que no existe en la teoría del discurso una conceptualización de la praxis. Laclau reconoce que su noción de discurso puede ser equiparada a la de "práctica" en otras teorías políticas https://www.youtube.com/watch?v=3KcidoIRNrQ (visitado: 3 de enero de 2016)
} 
- de Ípola, Emilio y Portantiero, Juan Carlos (1989 [1981]) “Lo nacional-popular y los populismos realmente existentes”. En Emilio de Ípola (1989) Investigaciones políticas, Buenos Aires, Nueva Visión.

- Dussel, E.D. (2009) Política de la Liberación, Vol II. Madrid: Trotta.

- exclusión. Madrid: Trotta

- Geras, N. (1988). Ex-marxism without substance: Being A real reply to Laclau and Mouffe. New Left Review, (169), 34.

- Glynos, J., Howarth, D., Norval, A. and Speed, E. (2009) 'Discourse Analysis: Varieties and Methods', ESRC National Centre for Research Methods, NCRM/014,

- Grant, J. (2011). Dialectics and contemporary politics: Critique and transformation from Hegel through post-Marxism Routledge: New York-London;

- Groppo, A. (2011) Tres versiones contemporáneas de la comunidad: Hacia una teoría política post-fundacionalista. Revista de Filosofía y Teoría Política (42), 49-68.

- Hegel, G. W. F. (1966). Fenomenología del espíritu. México: Fondo de cultura económica. Abada Editores/UAM ediciones. Madrid.

Hegel, G. W. F. (2011). Ciencia de la Lógica. Trad. Duque, F

- Hegel, G.W.F (1968) Ciencia de la lógica, trad. A. y R. Mondolfo, Solar / Hachette, Buenos Aires.

- Jameson, Fredric (2009). Valences of the Dialectic. Verso.

- Laclau, E \& Lilian Zac (2013/2014) “(A)notando la brecha: el sujeto de la política” Studia politicae, 31, pp. 5-39.

- Laclau, E (2003a [2000]). "Identidad y hegemonía: el rol de la universalidad en la construcción de lógicas políticas”, in: Laclau, Žižek \& Butler. Contingencia, hegemonía y universalidad. Buenos Aires, FCE pp. 49-94

- Laclau, E (2003b [2000]). "Estructura, historia y lo político", in: Laclau, Žižek \& Butler. Contingencia, hegemonía y universalidad. Buenos Aires, FCE

- Laclau, E (2014) Los fundamentos retóricos de la sociedad. Buenos Aires: FCE.

- Laclau, E. (1978 [1977]), Política e ideología en la teoría marxista. Capitalismo, fascismo, populismo, Madrid, Siglo Veintiuno.

- Laclau, E. (1980) "Populist Rupture and Discourse", Screen Education, 34, 87-93

- Laclau, E. (1983) 'The Impossibility of Society', Canadian Journal of Political and Social Theory, 7: 21-4.

- Laclau, E. (1987a). Psychoanalysis and marxism. Critical Inquiry, 330-333.

- Laclau, E. (1987b). Populismo y transformación del imaginario político en América Latina. Boletín De Estudios Latinoamericanos y Del Caribe, (42), 25-38.

- Laclau, E. (1989). "Politics and the limits of modernity".Social Text, (21), 63-82.

- Laclau, E. (1996), "¿Por qué los significantes vacíos son importantes para la politica?", en Emancipación y Diferencia, Buenos Aires, Ariel.

- Laclau, E. (2000 [1990]), Nuevas Reflexiones sobre la revolución de nuestro tiempo, Buenos Aires, Nueva Visión.

- Laclau, E. (2002a [1996]), "Muerte y resurrección de la teoría de la ideología", en Laclau, Misticismo, retórica y política, Buenos Aires, FCE.

- Laclau, E. (2002b [2001]), "Sobre los nombres de Dios", en E. Laclau, Misticismo, retórica y política, Buenos Aires, FCE.

- Laclau, E. (2002c [2001]), "Política de la retórica", en E. Laclau, Misticismo, retórica y política, Buenos Aires, FCE. 
- Laclau, E. (2005), La razón populista, Buenos Aires, FCE.

- Laclau, E. (2010). La articulación y los límites de la metáfora. Studia Politicae, (20), 13-38.

- Laclau, E. (2012) Antagonismo, subjetividad y política. En: Debates y Combates, Año 2, no. 3. p.7-37

- Laclau, E. y Ch. Mouffe ([1985] 2004), Hegemonía y estrategia socialista. Hacia una radicalización de la democracia, Buenos Aires, FCE.

- Laclau, E., \& Mouffe, C. (1987). Post-Marxism without apologies. New left review, 166(11-12), 79-106.

- Laclau, E; (2006). Por qué construir un pueblo es la tarea principal de la política radical. Cuadernos del CENDES, 23() 1-36. (Laclau 2006:104)

- Laclau, Ernesto. "Hegemonía y Antagonismo; el imposible fin de lo político." Santiago de Chile: Cuarto Propio

- $\quad$ Laclau, Ernesto. "Ideología y posmarxismo." Anales de la educación común (2006): 20-35.

- Marchart,O. (2009). El pensamiento político postfundacional. La diferencia política en Nancy, Lefort, Badiou y Laclau. Buenos Aires: Fondo de Cultura Económica.

- Mouzelis, Nicos. "Ideology and class politics: a critique of Ernesto Laclau." New Left Review 112 (1978): 45.

- Muñiz, M., \& Rossi, M. J. (2014). El fantasma del populismo a la luz de otro fantasma: Laclau lector de Hegel. In VIII Jornadas de Sociología de la UNLP (La Plata, 2014).

- Pérez Soto, C. (1997) Adversus: Foucault-Laclau-Bataille-Benjamin. UARCIS: Santiago de Chile. Perez Soto, 1997:32

- Pérez Soto, C. (2006). Sobre Hegel, Palinodia.Santiago

- Retamozo, M. (2011). Tras las huellas de Hegemón: usos de hegemonía en la teoría política de Ernesto Laclau. Utopía y praxis latinoamericana: revista internacional de filosofía iberoamericana y teoría social, (55), 39-58.

- Retamozo, M.; Stoessel, S. (2014). El concepto de antagonismo en la teoría política contemporánea. Estudios Políticos, Enero-Junio, 13-34.

- Sim, S., (2000). Post-marxism: An intellectual history (1st ed.). New York;London;: Routledge.

- Stewart, J. (1996). Hegel Myths and Legends. Northwestern University Press.

- Taylor, Ch (1975). Hegel.Cambridge University Press.

- Waiman, J. (2013). Dialéctica y ontología: repensando el antagonismo posmarxista desde la teoría crítica. Constelaciones. Revista de Teoría Crítica,5, 280-310.

- Wenman, M. A. (2003). Laclau or Mouffe? splitting the difference. Philosophy \& Social Criticism, 29(5), 581-606.

- Zemelman H. (1992) Horizontes de la razón (2t.), Barcelona: Anthropos

- Žižek, S. (1992). El sublime objeto de la ideología. Buenos Aires Siglo XXI.

- Žižek, S. (2006a). Against the populist temptation. Critical Inquiry, 32(3), 551-574.

- Žižek, S. (2006b). Impressive, but not striking! (Ernesto Laclau). Critical Inquiry, 33(1), 185-211.

- Žižek, S. (2012). Less than nothing: Hegel and the shadow of dialectical materialism. New York; London: Verso. 